\title{
Gestão internacional de recursos humanos: Adaptabilidade intercultural na expatriação de brasileiros
}

\author{
Patricia Asunción Loaiza Calderón ${ }^{1}$, Ana Lucia Malheiros Guedes e Rúbia Walquiria de Carvalho
}

Universidade do Grande Rio - UNIGRANRIO, Rio de Janeiro, RJ, Brasil

\section{DETALHES DO ARTIGO}

\section{Histórico do artigo:}

Recebido em 1 de outubro de 2015

Aceito em 18 de abril de 2016

Disponível online em 30 de agosto de 2016

Sistema de Revisão "Double Blind Review"

Editor científico:

Eduardo Eugênio Spers

Palavras-chaves:

Expatriados

Adaptação intercultural

Gestão internacional de recursos humanos

\begin{abstract}
RESUMO
Este artigo problematiza as experiências de brasileiros expatriados para desvendar os desafios e as oportunidades com os quais se deparam em outras culturas. Com base na literatura, destacamos a necessidade de humanizar o processo de internacionalização porque a expatriação é fenômeno multifacetado que requer abordagem multidisciplinar. Em termos empíricos, analisamos dados coletados por meio de entrevistas em profundidade com dezesseis expatriados. Os resultados indicam que o processo de expatriação é uma questão a ser tratada com mais atenção pela área de Gestão Internacional de Recursos Humanos. Destacamos os desafios da fragilidade da chamada adaptabilidade antecipada, das estratégias de retorno, do repatriamento e suas implicações para o plano de carreira, assim como, a necessidade de programas específicos de treinamento intercultural. Por outro lado, os relatos dos expatriados registram conotações positivas as oportunidades profissionais e pessoais das missões internacionais. Ao considerar estes resultados, a área de Gestão Internacional de Recursos Humanos poderia aproveitar a intensa experiência dos expatriados para reformular políticas e práticas e, consequentemente, usufruir do mindset global.
\end{abstract}

(C) 2016 Internext | ESPM. Todos os direitos reservados!

\section{Introdução}

Diante do fenômeno multifacetado da globalização, a crescente internacionalização das empresas brasileiras impulsionou a área de Gestão Internacional de Recursos Humanos (GIRH). Seja para atender às necessidades específicas da mobilidade internacional e os desafios decorrentes, como por exemplo, da integração de culturas nas fusões e aquisições transfronteiras e nas alianças estratégicas, GIRH tornou-se uma área de estudo relevante e estratégica no âmbito de gestão internacional no Brasil. Em decorrência disso, o fenômeno da expatriação - que envolve o deslocamento de profissionais da empresa matriz para países de operação e vice-versa - tem se intensificado. As multinacionais brasileiras continuam aumentando o índice médio de internacionalização nos últimos anos, em aproximadamente $2,0 \%$ por ano (FDC,

\footnotetext{
${ }^{1}$ Contato do autor: Email: patricialc@hotmail.com

2014). Além disso, em relação aos dados de 2014, houve um aumento no número de países de entrada, de 26 para 33 (FDC, 2015). Isso sugere uma perspectiva positiva de expansão internacional e, evidentemente expatriação de brasileiros.

Entretanto, compreender a experiência de ser executivo no exterior, conforme Joly (2012) requer um olhar abrangente e multidisciplinar. A expatriação apresenta uma série de desafios e de oportunidades que este artigo busca problematizar com base na análise dos relatos das vivências e experiências de brasileiros expatriados frente as iniciativas que a área de GIRH tem utilizado para acompanhar esse processo.

Este artigo contribui para a literatura de GIRH pelo foco em expatriados brasileiros, portanto, evidencia aspectos de gestão à brasileira em uma área de conhecimento colonizada pelas práticas 
hegemônicas anglo-americanas. Em paralelo, destacamos a necessidade do resgate da dimensão humana na gestão internacional, para evitar que pessoas se tornem apenas um recurso (Spanger, 2012). Em termos práticos, o artigo indica potencialidades para melhor desempenho das empresas em processo de internacionalização, e particularmente, para gestores de áreas internacionais, profissionais de gestão de pessoas, consultores, bem como os expatriados.

Este artigo está estruturado em quatro partes além desta breve introdução. Primeiro, apresentamos a fundamentação teórica do tema seguida da metodologia adotada no estudo. A seguir, descrevemos e analisamos os resultados obtidos para, por fim, apresentarmos as considerações finais e sugestões para futuras pesquisas.

\section{Gestão Internacional de Pessoas: implicações para a dimensão humana}

A vasta literatura de GIRH está focada prioritariamente nas empresas multinacionais (EMNs) abrangendo as seguintes temáticas: atitudes dos executivos na gestão das subsidiárias (Perlmuter, 1969); processo de adaptação dos expatriados, (Tung, 1981; Black, Mendenhall e Oddou, 1991); estudos comparativos de GRH entre diversos países, salientando os aspectos culturais (Hofstede, 2003); modelos de GIRH (Schuler e Tarique, 2007) notadamente funcionalistas e que pregam ser possivel a transferência das melhores práticas. No entanto, autores críticos como Peltonen (2006) apontam a necessidade de levar em consideração a variedade contextual quando se trata de implementar políticas de gestão no nível local (Peltonen, 2006) questionando a existência de um modelo universal de GIRH. Além disso, como a literatura contemporânea de GIRH considera os expatriados como "recursos estratégicos" as pesquisas se desviaram dos problemas humanos da adaptação intercultural. Este tema, segundo Peltonen (2006) precisa ser retomado.

Para Peltonen (2006, p. 532) o campo de GIRH “é uma ramificação dos estudos que investiga o arranjo e as práticas de gestão de pessoas nas organizações em contextos interculturais" e estaria localizada na interseção de Negócios Internacionais (NI) com a Gestão de Recursos Humanos (GRH) e o Comportamento Organizacional (CO). Consequentemente, acreditamos que GIRH devem levar em consideração tanto o indivíduo e a organização, quanto o contexto multifacetado de negócios como elementos constitutivos de um mesmo fenômeno.

Aceleração da internacionalização de empresas brasileiras nas últimas décadas acabou por reproduzir um padrão dominante de estratégia de negócios e de competitividade internacional que desumaniza às organizações. Em decorrência disso, as pessoas são tratadas como objetos (Chanlat, 2012). São "esquecidas" certas dimensões humanas como: a cognitiva, a da linguagem, a dimensão espaço temporal, a dimensão psíquica e afetiva, a dimensão simbólica, a dimensão da alteridade e a dimensão psicopatológica que se manifestam na expatriação.

Segundo Joly (2012, p. 84) as pessoas que vivenciam uma designação internacional podem atravessar uma "desestruturação-reestruturação da personalidade" que afeta a identidade pessoal do expatriado e se manifesta em cada uma das fases da experiência no estrangeiro. $\mathrm{O}$ autor apresenta quatro etapas - encantamento, negativismo extremo, guardar distancia ou integrar-se e choque da volta que "permeiam" um processo de expatriação, as mesmas que interagem de maneira diferente e que podem ser, segundo ele, generalizáveis em todas as experiências "de exposição a culturas estrangeiras" (Joly, 2012, p. 92).

Por outro lado, deve-se considerar a falta de sensibilidade e cegueira dos profissionais da área de RH em relação às implicações do processo de expatriação para o expatriado por desconhecimento e/ou falta de vivência e experiência internacional (Freitas e Dantas, 2010; Lima e Braga, 2010). Conforme destacam Silva, Orsi e Nakata (2013) a área de GIRH tem como objeto de estudo privilegiado o expatriado. No entanto, o aspecto cultural e de adaptação ainda é um desafio para as empresas.

\subsection{Principais trabalhos de GIRH no Brasil}

Embora as empresas brasileiras tenham aumentado suas operações ao redor do mundo e sejam consideradas líderes entre as denominadas multilatinas (Cazurra, 2010; Casanova, 2010) apresentam dificuldades quando se trata da GIRH (Fleury e Fleury, 2012). Isso porque estariam negligenciando aspectos importantes para o êxito de $\mathrm{NI}$, como por exemplo: os processos de recrutamento e seleção (Salgado, 2014); a preparação e o treinamento dos expatriados e repatriados e de suas 
famílias (Lima e Braga, 2010; Spanger, 2012); as políticas de recompensas e benefícios dos funcionários (Orsi, 2010); as políticas de desenvolvimento e de carreiras para o funcionário internacional (Lima e Braga, 2010; Nogueira, Barreto e Delgado, 2013); a avaliação do desempenho internacional (Salgado, 2014); a diversidade da mão de obra internacional; (Lisboa, 2014); o clima ético e legal da GIRH (Aguzzoli, 2008). Neste contexto, a falta de alinhamento da estratégia de RH com a estratégia organizacional tem sido destacada por vários autores (Aguzzoli, 2008; Nogueira, Barreto e Delgado, 2013; Tanure e Duarte, 2006) como o principal problema. A falta de alinhamento com a área de $\mathrm{RH}$, deve-se à perpetuação de um modelo hegemônico de gestão, segundo o qual o "humano" é preterido e, em contrapartida, os aspectos econômicos, ou da "firma" são privilegiados.

Apesar da relevância do humano, destacada neste artigo, a mesma não aparece nas práticas cotidianas das organizações brasileiras e, provavelmente, isto é uma consequência da formação de algumas escolas de administração que tiveram a sua origem, conforme Caldas, Tonelli e Braga (2009, p. 13), a partir de "acordos bilaterais entre o governo brasileiro e escolas norte-americanas" cuja tradição de pesquisa é predominantemente funcionalista. Daí a necessidade de (re)pensar a GP no contexto brasileiro para que contemple aspectos singulares do humano que têm sido negligenciados ao darmos destaque aos aspectos meramente funcionais. Wood, Tonelli e Cooke (2012, p. 124) apontam que a área de GP no Brasil precisa se libertar da "herança colonial, sem perder a permeabilidade saudável ao conhecimento originado no exterior e reconstrua a sua identidade, pautando suas ações por valores humanistas, por uma consciência ampliada da realidade e pela simplicidade". Em suma, os autores instigam a pesquisa rigorosa da realidade local, para termos resultados consistentes com o lócus, postura esta que compartilhamos.

\section{Adaptabilidade intercultural}

Muitas pesquisas sobre o "ajustamento" na expatriação utilizam o modelo teórico de Black, Mendenhall e Oddou (1991). Nesse modelo, os autores consideram que o "ajustamento" deve acontecer em dois momentos. $O$ primeiro aconteceria no país de origem e, o segundo quando o expatriado está já no país hospedeiro. No entanto, o termo "adaptabilidade" parece ser mais apropriado. Ao considerar a adaptabilidade na origem, estaríamos falando da preocupação da organização em possuir uma política idônea de práticas de GIRH, entre as quais a seleção, por exemplo, seria feita não apenas levando em consideração competências técnicas, mas também, as competências interculturais e intraculturais.

O modelo de Black, Mendenhall e Oddou (1991) aponta quatro tipos de adaptabilidade pelos quais os expatriados podem sentir maior ou menor dificuldade:

- Adaptabilidade Geral-Fora do trabalho: envolve novidade cultural da sociedade, isto é, diferenças a partir de valores básicos como, religião, crenças, normas, papeis femininos e masculinos; o reconhecimento de fatores de adaptabilidade referentes aos familiares.

- Adaptabilidade Individual: compreende aspectos como auto eficácia, resistência ao estresse cultural, manutenção da competência técnica e mecanismos de substituição; habilidade para relacionar-se com pessoas apesar das diferenças culturais o que envolve autoconsciência desenvolvida e percepção aguçada do outro.

- Adaptabilidade Interativa-Profissional: diz respeito à clareza de papeis, entendimento de novas tarefas, demandas, necessidades e deveres; o discernimento sobre as diferenças entre a empresa no país de origem e na nova cultura.

- Adaptabilidade Organizacional Cultural: relacionada às diferenças entre a cultura organizacional da filial e a cultura da matriz, compreende também o apoio social ao expatriado, isto é, o acompanhamento na chegada, no trabalho e o apoio logístico no que se refere a moradia, serviços bancários, de saúde e escolares.

Mendenhall, Punnett e Ricks (1995) sinalizam que pesquisadores de GIRH têm estudado fatores chaves de sucesso para expatriados, tentado isolar a natureza exata da adaptação internacional e, identificado as principais habilidades que contribuem para a adaptação do expatriado a uma nova cultura social e de negócios.

No caso do treinamento intercultural, consideramos relevante a proposta de Fraga (1998) 
que discute a necessidade de enxergar a educação intercultural no sentido da mundialização da cultura, visando à humanização da globalização. Os quatro âmbitos e movimentos culturais propostos por Fraga e Esteves (2004) - multicultural, intracultural, intercultural e transcultural -, constam na Tabela 1.

Tab. 1

Âmbitos e Movimento Interculturais

\begin{tabular}{ll}
\hline Movimento & Descrição \\
\hline Multicultural & $\begin{array}{l}\text { Constatação da presença dinâmica de } \\
\text { diferentes culturas e subculturas em uma } \\
\text { região, um país ou empresa. }\end{array}$ \\
\hline Intracultural & $\begin{array}{l}\text { Olhar, sentir, vivenciar uma cultura por } \\
\text { dentro: de uma equipe, organização, } \\
\text { comunidade ou nação. }\end{array}$ \\
\hline Intercultural & $\begin{array}{l}\text { Movimento cultural que possibilita a troca } \\
\text { entre diferentes culturas e/ou subculturas. }\end{array}$ \\
\hline Transcultural & $\begin{array}{l}\text { Trânsito suave e harmônico por diferentes } \\
\text { culturas e subculturas, respeitando as } \\
\text { singularidades de cada uma delas, para que } \\
\text { as trocas sejam produtivas e éticas em } \\
\text { busca do sentido comum, em direção da } \\
\text { co-humanidade. }\end{array}$ \\
\hline
\end{tabular}

Fonte: Fraga e Esteves (2004, p. 280).

Partimos do pressuposto que a compreensão e vivência desses movimentos, antes, durante e no retorno de um processo de expatriação, numa perspectiva de educação intercultural, conforme Fraga e Esteves (2004) possibilitariam uma melhor compreensão do "outro". A partir do reconhecimento das diferenças, do autoconhecimento, da predisposição para a troca e para o transito suave entre culturas, respeitando aquilo que é diferente, mas que é essencialmente humano. Desta forma, acreditamos ser necessário complementar o modelo de Black, Mendenhall e Oddou (1991) conforme consta na Figura 1.

Reforçamos a compreensão desses quatro movimentos não apenas em termos teóricos, mas principalmente segundo uma leitura fenomenológica do mundo (Fraga, 2009) onde cada um dos expatriados, repatriados, gestores de $\mathrm{RH}$ compreendam esse processo em si mesmo, na sua realidade singular e concreta.

\section{Políticas e práticas de Gestão do expatriado}

As políticas e práticas de Gestão do Expatriado devem humanizar as relações e auxiliar os funcionários a aceitar e conviver com valores que, muitas vezes se chocam com a identidade e os valores próprios. Embora a GIRH seja um assunto "recente e incipiente" (Silva, Orsi e Nakata, 2013, p. 51),

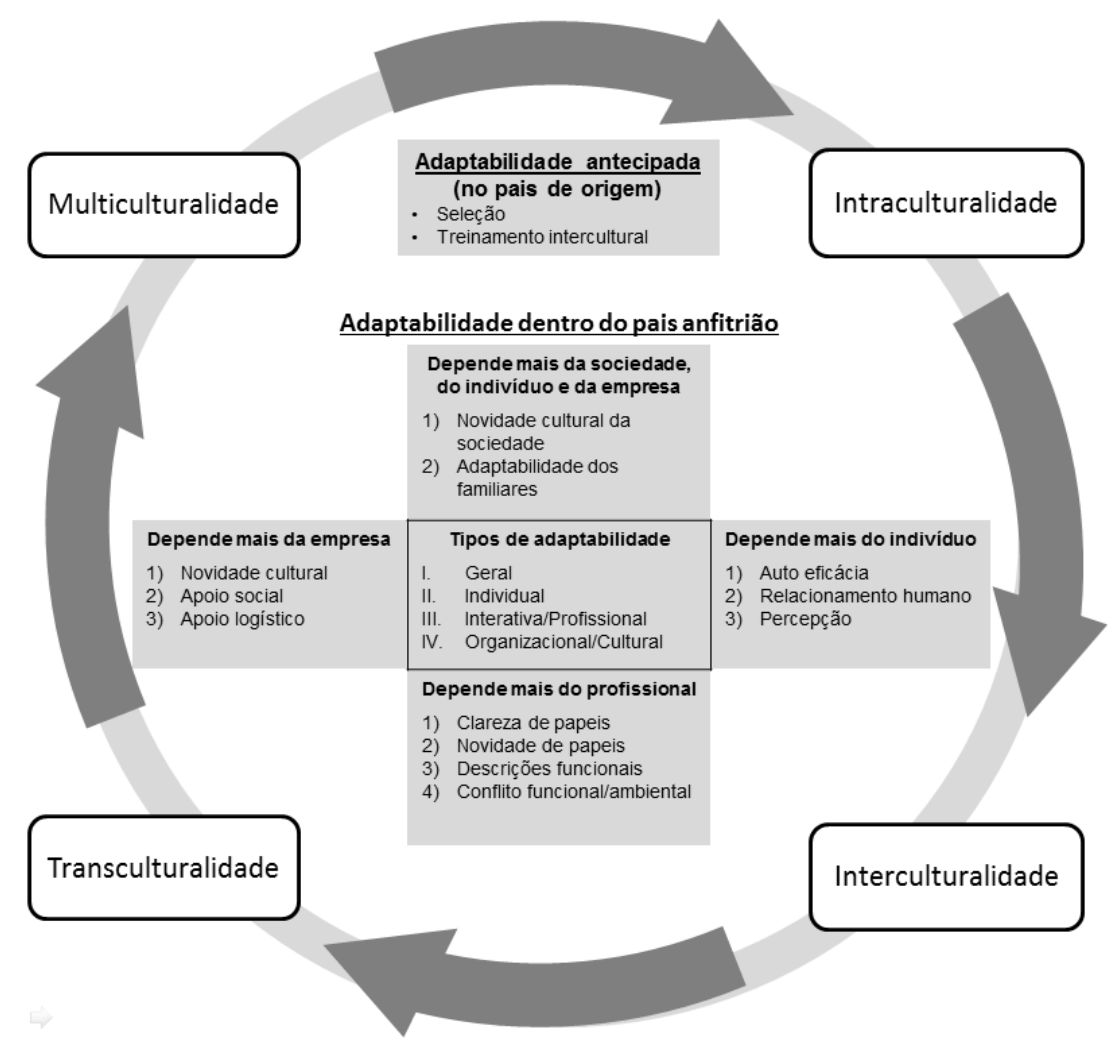

Fig. 1

Dimensões da Adaptabilidade Intercultural: contribuições e complementos

Fonte: Adaptado com base em Mendenhall, Punnett, e Ricks (1995); Fraga e Esteves (2004). 
relativamente novo e pouco explorado no Brasil (Aguzzoli, 2008) é um tema contemporâneo complexo (Bianchi, 2011) que requer pesquisas empíricas para fundamentar as políticas e práticas de GIRH. Primeiramente no que se refere à seleção dos candidatos à expatriação, Nogueira, Barreto e Delgado (2013) afirmam que não existem critérios específicos para uma seleção global. No entanto, Manzon, Jaeger e Kato (2010, p. 33) destacam a dominância do "critério técnico sob o cultural". Já Tanure, Evans e Pucik (2007) indicam que nas empresas brasileiras o critério considerado é a confiança no expatriado, no entanto, "isso não é suficiente", uma vez que as empresas não levam em conta a "habilidade intercultural do candidato e a disposição da família de viver em um país estrangeiro" (2007 p. 180). Aspectos fundamentais para uma expatriação bem-sucedida, em termos do equilíbrio emocional do expatriado e da sua família.

Segundo Corsetti (2013) há unanimidade nas pesquisas sobre a ausência de ações concretas que levem em consideração o treinamento intercultural, sendo comum o treinamento técnico, o que mostra um "desalinhamento entre as práticas de Gestão de Pessoas e as expectativas dos expatriados" (p.62) Essa carência afetará sua adaptabilidade, uma vez que "confronta sua bagagem pessoal e sua trajetória profissional com hábitos e indivíduos estranhos" (Corsetti, 2013, p.64). Por outro lado, Rosal (2015) afirma que a gestão da remuneração reflete a forma como o processo de expatriação é compreendido pelas empresas, que "adotam uma visão unilateral à medida que o diálogo entre empresa e o expatriado não é contemplado nessa etapa do processo". $(p, 14)$ Desta forma, restringem a possibilidade de ofertar e negociar recompensas e/ou benefícios que minimizem perdas e riscos originados da experiência de viver no exterior.

Na perspectiva do expatriado, existem desafios e oportunidades que devem ser compreendidos. Gallón, Garay e Bittencourt (2012) identificam: inadequada adaptação do cônjuge ou da família; inadequada adaptação do expatriado devido ao choque cultural; dificuldade do expatriado para atender às exigências do seu cargo; competência técnica insuficiente para o cargo; falta de motivação para trabalhar no exterior; falta de maturidade emocional; carência de habilidade de comunicação e socialização. Muritiba Muritiba Campanário Albuquerque (2010) mencionam, também, as diferenças de idioma. Entre as oportunidades, a expatriação bem-sucedida promove 0 desenvolvimento pessoal e profissional do indivíduo que pode ser caracterizado como "um processo transformacional para uma pessoa" (Bianchi, 2011, p.10).

Lamentavelmente se não compreendem a natureza da expatriação e se ignoram as dimensões de adaptabilidade intercultural, os âmbitos e movimentos interculturais, a tendência, conforme apontam as pesquisas, é a miopia da área de GIRH e, consequentemente, a ausência de políticas e práticas que levem em conta a relevância do humano na gestão.

\section{Metodologia}

Optou-se por uma pesquisa de natureza qualitativa porque pretendemos não apenas descrever as vivências e experiências dos expatriados, mas compreender a "essência" desse fenômeno desde a perspectiva de brasileiros expatriados incluindo as suas vozes num processo interativo que se da num contexto natural onde, o fenômeno, essencialmente humano transparece à luz do diálogo (Creswell, 2014). Em outras palavras, a pesquisa qualitativa oportuniza uma descrição "densa" que permite explicações sobre o que está acontecendo (Gibbs, 2009).

A pesquisa se iniciou com pesquisa bibliográfica que permitiram o embasamento teórico e metodológico. A elaboração do instrumento de coleta de dados foi realizada em coerência com as recomendações de McCracken (1988) para entrevista em profundidade. O roteiro composto de 27 questões divididas em 6 seções, foi elaborado principalmente a partir de Mendenhall, Punnett, e Ricks (1995); Fraga e Esteves (2004) e Joly (2012). Foi testado com uma entrevistada escolhida pelo fato de já ter sido expatriada em três oportunidades e refinado a partir das sugestões de Gibss (2009), antes de sua aplicação aos outros entrevistados. Isso incluiu a revisão e eliminação de questões parecidas assim como a formulação de outras questões mais objetivas e claras.

O acesso aos entrevistados foi inicialmente difícil. Aproveitamos dos contatos de uma das autoras que trabalhava numa EMN. Esse primeiro contato indicou outras pessoas que tinham sido expatriadas ou que lidavam diretamente com esse processo na empresa. Após iniciadas as primeiras entrevistas houve indicação espontânea dos próprios entrevistados de 
outras pessoas que poderiam contribuir com a pesquisa, seguindo a estratégia de "bola de neve" (Creswell, 2014, p. 131).

Os entrevistados foram informados previamente do objetivo da pesquisa e a autorização para gravar foi feita por meio da assinatura de um protocolo. Garantimos a confidencialidade dos participantes com nomes fictícios, conforme consta no Tabela 2: posteriormente, a partir da gravação em áudio. Os entrevistados foram contatados por telefone e/ou email para marcar as entrevistas no local e horário de conveniência, na cidade do Rio de Janeiro.

A transcrição, categorização e análise dos resultados foram realizadas segundo a técnica de Análise de Conteúdo Categorial (Bardin, 2011; Dellagnelo e Silva, 2005). Para mecanizar as tarefas

Tab. 2

Perfil Demográfico dos Entrevistados

\begin{tabular}{ccll}
\hline № & Nome & Cargo Atual & Experiência Internacional \\
\hline 1 & Antônio & Trader de Petróleo & Argentina (5 anos); Singapura (5 anos) \\
2 & Beatriz & Assistente de Diretor Corporativo & EEUU (4 meses); Argentina (4 anos); Inglaterra (2 anos) \\
3 & Celso & Ex. Diretor de RH, Universidade Corporativa e RHI. & Bolívia (5anos); Chile (2 anos) \\
4 & Diego & Coordenação de Abastecimento & Inglaterra (2 anos) \\
5 & Eliane & Analista de comercialização e logística & Singapura (duas semanas); Londres (2 anos) \\
6 & Francisco & Gerente de Contabilidade & Angola (3 anos e meio); Nigéria (4 anos) \\
7 & Giulia & Embarcada em navios & 11 países diversos (ultimo país Italia-8 meses) \\
8 & Hélio & Analista de Mercado & Inglaterra (2 anos e três meses) \\
9 & Irineu & Gerente Operacional & Argentina (2 meses) \\
10 & Jayme & Capitão de Fragatas & Portugal (3 anos) \\
11 & Kevin & Trader de óleo combustível & Bolívia (1 ano) \\
12 & Larissa & Enfermeira do Trabalho & Peru (1 ano); Argentina (9 meses); Chile. (1 ano) \\
13 & Marcos & Engenheiro de Produção & Inglaterra (3 anos) \\
14 & Nelson & Administrador & EEUU( 2 anos e 3 meses) \\
15 & Osíris & Engenheiro de Produção & França (9 meses) \\
16 & Pedro & Gerente de Compras & Colômbia (4 anos e 6 meses) \\
\hline
\end{tabular}

Fonte: Elaboração própria das autoras.

Foram entrevistados 16 brasileiros, no período de setembro a dezembro de 2014, que atuaram como expatriados em países da América do Sul, América do Norte, Ásia, Europa ou África. Cada entrevista teve a duração média de uma hora. Todas as entrevistas foram realizadas em português e, transcritas, de organização e arquivamento de textos utilizou-se o SADQ (software de análise de dados qualitativa) Atlas TI versão 6.0. Este software permitiu, além de armazenar e manipular os textos, a criação de códigos a partir da transcrição das falas dos

Tab. 3

Categorias temáticas centrais da pesquisa

\begin{tabular}{lll}
\hline Categoria & Descrição & Autor de suporte \\
\hline Fases da experiência no estrangeiro & $\begin{array}{l}\text { Relacionada às 4 etapas que permeiam o processo de } \\
\text { expatriação. }\end{array}$ & Joly (2012) \\
\hline $\begin{array}{l}\text { Dimensões da adaptabilidade } \\
\text { intercultural }\end{array}$ & $\begin{array}{l}\text { Agrupam variáveis que influenciam a grau de } \\
\text { adaptação do expatriado. }\end{array}$ & $\begin{array}{l}\text { Mendenhall, Punnett, e Ricks } \\
\text { (1995);Fraga e Esteves (2004) }\end{array}$ \\
\hline Políticas e práticas de GIRH & $\begin{array}{l}\text { Especificamente atreladas a recrutamento e seleção; } \\
\text { treinamento, plano de carreiras e remuneração. }\end{array}$ & Lima e Braga (2010) \\
\hline Características dos brasileiros que & Características, que na opinião dos entrevistados, & Tanure, Evans e Pucik (2007) \\
ajudaram no processo de adaptação & facilitaram a sua adaptação. & \\
\hline Oportunidades, desafios e & Nesta categoria registraram-se os ganhos obtidos com & Gallón, Garay e Bittencourt \\
aprendizados da expatriação. & a expatriação, tanto no âmbito pessoal como & (2012); Muritiba et. al (2010); \\
& $\begin{array}{l}\text { profissional, assim como os empecilhos com que se } \\
\text { deparam durante o processo. }\end{array}$ & Bianchi (2011) \\
\hline Dimensão sensorial, sentimentos e & Esta categoria está relacionada à percepção do mundo & Merleau-Ponty (2011); \\
emoções. & pelos sentidos (audição, tato, olfato, paladar, visão) & Chanlat (2012) \\
& assim como a manifestação de sentimentos e emoções. & \\
\hline
\end{tabular}

Fonte: Elaboração própria das autoras. 
entrevistados e a redação de memorandos que possibilitaram uma análise mais refinada dos dados.

O processo de codificação inicial, com base na revisão de literatura, continha uma lista de 25 categorias "a priori" criadas para facilitar a codificação e a análise dos dados e, na medida em que foram reexaminadas, emergiram outras que complementaram a explicação e compreensão do fenômeno expatriação. Assim, foram analisadas as categorias "a priori" e as "emergentes", para serem combinadas e integradas em seis categorias temáticas centrais que são descritas na Tabela 3:

Logo, seguiu-se a etapa de interpretação, "momento da reflexão, da intuição com embasamento nos materiais empíricos e nos referenciais teóricos disponíveis [...] Isto é, buscar os sentidos daquilo que os dados tratados nos revelam" (Dellagnelo e Silva, 2005, p. 113). A seguir apresentamos a descrição e análise dos resultados obtidos.

\section{Descrição e Análise dos Resultados}

Com base na consolidação das análises, apresentamos os resultados organizados por categorias temáticas.

\subsection{Fases da Experiência no Estrangeiro}

Foi possível constatar que os expatriados não passam necessariamente pela etapa de "encantamento", conforme Joly (2012). Isto depende do lugar de destino e das condições oferecidas pela cultura hospedeira. Quando a designação é para um país desenvolvido a tendência é uma reação inicial positiva e, negativa, quando o país de destino é menos desenvolvido que o país de origem do expatriado, como ilustram os depoimentos:

\section{Impacto positivo:}

"Não conhecia Londres. Acho que o primeiro impacto é a questão da organização; particularmente achei os ingleses extremamente educados [...] o impacto foi de surpresa de você ver um país que realmente acolhe muito bem todo mundo". (Pedro)

\section{Impacto negativo:}

"Cheguei à noite e não conseguia ver os arredores da cidade. Quando acordei no segundo dia, estava numa casa maravilhosa [...] e o entorno era todo de rua de barro com esgoto a céu aberto e palafitas, casas sem a mínima condição de higiene. Então isso me causou um impacto do tipo assim: como essa sociedade pode ser tão dividida, uma casa de ricos e circundada por um território tão pobre?" (Francisco)

Embora não tenham sido relatadas situações de negativismo extremo, ficou evidente que para alguns dos entrevistados, conforme Joly (2012, p. 90), "surgem as tensões entre as pulsões da personalidade". Transparece, por exemplo, na fala de um deles a "sensação de ser estrangeiro" como sendo o maior estranhamento:

"Gostava de estar ali, mas depois de certo tempo, sabe a sensação de que ali não é meu lugar, eu sei que aquilo vai ter que ser passageiro, porque eu não me sinto parte daquilo". (Beatriz)

As dificuldades com a diferença de idioma (Gallon, Garay e Bittencourt, 2012), clima, alimentação, desconhecimento do local, ficaram evidentes em diversos relatos, como este:

"Minha maior dificuldade era falar com os argentinos, pois eu não falo nada de espanhol, eu ficava com vergonha, meio acanhado. Tinha receio até de ir ao mercado, comprar alguma coisa, mas depois fui arriscando, fazendo mímicas" (Jayme).

Notamos esforços de integração ao invés de isolamento (Joly, 2012) em grande parte dos relatos, por exemplo: frequentar festas locais, utilizar roupas típicas, e adotar hábitos da cultura local foram mecanismos que ajudaram na inserção na cultura hospedeira.

\subsection{Dimensões da adaptabilidade intercultural}

Foi identificado nos resultados que a maior dificuldade está relacionada com a dimensão "Adaptabilidade Geral" (Black, Mendenhall e Oddou, 1991), como ilustra o depoimento:

"Minha primeira dificuldade foi em relação à comunicação, apesar de falarmos português [...] a gente tem um problema de linguística sério. Tem coisas que são simples pra nós brasileiros, mas pra eles não, pois são interpretados a risca do que se fala. [...] Tivemos uma situação onde eu estava sentado, num restaurante jantando com um amigo, ele pediu um prato de comida e então eu me virei para o garçom e disse que queria do mesmo. Para minha surpresa veio um prato só. $E$ quando questionei ao garçom ele disse que eu havia falado que ia comer do mesmo prato. E aqui no Brasil, isso significa que eu ia comer um prato 
igual ao do meu amigo, seriam dois pratos e não um prato só". (Francisco)

Um facilitador foi o papel da família, considerado imprescindível por ser a base de conforto e controle emocional do expatriado. Como afirmam Tanure, Evans e Pucik (2007), quando o expatriado não está acompanhado da sua família, o sentimento de saudade, aflora nas falas dos entrevistados:

"Essa parte foi difícil porque eu senti muita saudade. Eu ligava todo dia [...] Só que não adiantava muito, pois você não pode abraçar sua esposa, seu filho, isso era chato no final eu já estava doido pra voltar". (Antônio)

$\mathrm{Na}$ dimensão Adaptabilidade Individual, os entrevistados expressaram ter como característica primordial para uma expatriação: "curiosidade", "flexibilidade", "facilidade de comunicação", "diplomacia", "humildade", "ter a mente aberta para absorver o que outras culturas podem nos trazer de conhecimento e experiência de vida pessoal e profissional", "ser educado", "extrovertido", "ter jogo de cintura", ser "persistente", "comprometido" e "pragmático". Para ilustrar segue depoimento:

"Tenho uma característica [...] meu pragmatismo. O que eu vi, eu procurei fazer, eu sabia que tinha uma missão ali e tinha os objetivos do trabalho a serem atingidos e tinha que me adaptar da melhor forma possível. Ao invés de reproduzir na França o Brasil, procurei aproveitar da melhor maneira possivel o que aquele país tinha a me oferecer, ao invés de lamentar que não tivesse praia como no Rio de Janeiro, eu abracei uma característica física daquela cidade, que era as montanhas, então fazia caminhadas naquela região montanhosa e era um hábito dos locais que adoravam fazer aquilo". (Osíris)

Com relação ao tipo de Adaptabilidade Interativa/Profissional, podemos citar os esforços dos profissionais que foram expatriados em adaptar-se à estrutura organizacional e vencer os desafios até se sentirem confortáveis no novo ambiente de trabalho em questões como a postura profissional:

"Quando comecei a trabalhar a língua era a barreira, outra [...] a questão da postura, eu sou muito expansivo então eu, meio que quando comecei a trabalhar, lutei para me policiar para não ter esse comportamento aqui, [...] achei que eu tinha que me acomodar à cultura". (Marcos)

Na dimensão Adaptabilidade Organizacional/Cultural foi constatada que nove dos expatriados sentiram-se "razoavelmente" atendidos em termos de apoio social e logístico:

\begin{abstract}
"O apoio que a empresa me deu, não foi perfeito, mas foi bem grande e a minha adaptação foi mais fácil nesse e período de expatriação [...] Eles fizeram todo o trâmite burocrático, me ajudaram com moradia, [...] me ajudaram com um automóvel, isso foi muito bom pome dava uma autonomia e facilitava o deslocamento, apesar do serviço público ser muito bom, por eu não conhecer inicialmente a cidade, o carro foi um facilitador para mim".(Osíris)
\end{abstract}

No entanto, a área de GIRH deve dar um suporte devidamente planejado ao expatriado e a família. Mecanismos de seguimento são necessários, uma vez que foram relatados casos de serviço inadequado por parte de corretores que cuidavam da moradia dos expatriados e/ou do traslado de bagagens e mobília.

Por outro lado, evidenciaram-se diferenças entre a sede da empresa e a filial:

"O dia a dia é bem diferente de você estar na sede da corporação, então lá [Inglaterra] eu tinha mais autonomia [...] Aqui na sede, a gente é muito mais interrompida por prioridade dos outros, [...] a gente tem mais deveres corporativos [...] e mais interrupções e lá não, lá eu conseguia me concentrar no meu trabalho". (Beatriz)

A compreensão e vivência dos "quatro âmbitos e movimentos culturais" propostos por Fraga e Esteves (2004), ilustrados na tabela 1, manifestaram-se nos resultados, pois a expatriação possibilitou uma melhor compreensão do "outro".

"Tem dois aprendizados fundamentais, um é a diversidade cultural [...] é diferente saber, de vivenciar [...] entender a riqueza dessa diversidade cultural de lidar em ambientes multiculturais foi um aprendizado fantástico [...] outro grande aprendizado [...] é de conhecer a nós mesmos no Brasil". (Celso)

Outro ponto destacado pela maioria dos entrevistados é que a experiência da expatriação permitiu-Ihes vivenciar a diversidade cultural.

6.3 Políticas e práticas de Gestão Internacional de Pessoas

Todos os entrevistados informaram sobre a existência de algumas ações por parte da empresa, para informá-los sobre o novo país. Entretanto, 
tratava-se apenas de informações básicas, feitas através de cartilha. $\mathrm{O}$ aspecto cultural por meio de um Programa de Treinamento Intercultural, conforme sugerem Fraga (1998), Tanure, Evans e Pucik (2007), não foi trabalhado com os entrevistados. Apesar dos relatos de algumas iniciativas de treinamento que abordaram aspectos culturais de maneira considerada "informal", "mal feita" e por demais sucintas, conforme os depoimentos que seguem:

"Simplesmente técnico [...] a parte cultural é zero, não existe". (Tiago)

"Cursos e palestras de capacitação intercultural, nunca houve". (Antônio)

Apenas depois do questionamento sobre o aspecto cultural é que perceberam que esse tipo de informação fez falta na adaptação do expatriado. Embora tenha sido vista como positiva a iniciativa de uma viagem previa ao lugar da expatriação em companhia da família.

Sobre o processo de seleção, foi perceptível a simplificação com foco no critério técnico, conforme apontado por Manzon, Jaeger e Kato (2010) assim como a natureza de "cargo de confiança" em detrimento de pessoas com competências comportamentais e interculturais (Tanure, Evans e Pucik, 2007; Corsetti, 2013).

"Jamais vamos expatriar um operador de refinaria ou um engenheiro de manutenção, não faz nenhum sentido expatriar porque você encontra isso no país da filial. A gente expatria pessoas que a gente chama de posições críticas onde a confiança tem que ser total". (Celso)

Além disso, segundo a entrevistada (Beatriz), que ocupou cargo de nível estratégico com "exposição internacional" o fato de ser "experiente" e "madura" a habilitou para ser escolhida numa missão a um país da Europa.

Foi evidenciada a ausência de uma política de repatriação condizente com Lima e Braga (2010). As organizações negligenciam o retorno dos expatriados, fragilizam a estrutura de gestão de pessoas, e demonstram descaso para com a situação dos repatriados. Desta forma, manifestam despreparo no planejamento e a inexistência de um plano de carreiras após a expatriação. A impressão de alguns entrevistados é de que a empresa não cumpre o papel de acompanhamento que deveria ser continuo, como ilustra a seguinte fala:
"A sede coloca você aqui, e depois te cobra pelos resultados. Ninguém te pergunta se você está bem [...] Falta sensibilidade de a sede perceber isso". (Irineu)

No caso de falta de estrutura organizacional para o repatriamento é preciso atentar para prejuízos além das questões pessoais/profissionais, pois a empresa também perde em know how necessário aos avanços no processo de internacionalização. Cabe aqui destacar Chanlat (2012), Fraga (2009), Wood, Tonelli e Cooke (2012), Gaulejac (2007) por chamarem a atenção do "humano" na globalização e na formação internacional.

6.4 Características dos "brasileiros" que ajudaram no processo de adaptação

Todos os entrevistados destacaram que o brasileiro é caloroso, comunicativo e adaptável. Também destacaram que a flexibilidade do brasileiro é uma característica fundamental para o sucesso na expatriação. Salientaram que essa facilidade de comunicação do brasileiro ajuda-o a suportar problemas e choques culturais, além da saudade de pessoas próximas. (Tanure, Evans e Pucik, 2007):

"Sou uma pessoa flexível, diria que bastante open mind, de mente aberta pra muitas coisas, ainda tenho meus preconceitos, muitos foram por água abaixo, porque a gente acaba lidando com diferenças, senão você não troca informação, perde a oportunidade de conhecer pessoas". (Hélio)

"Eu tive a oportunidade de viajar por regiões no interior da China, ver e provar pratos exóticos (carne de burro, gelatina salgada, etc.), conhecer os costumes na mesa, etc. A disposição em acompanhar as empresas e compartilhar com seus representantes um almoço ou jantar, alegrou sobremaneira os chineses, quebrou certas barreiras e com certeza facilitou futuros negócios". (Antônio)

Outra característica evidente do brasileiro é o seu otimismo. Todos os entrevistados, mesmo enfrentando muitos problemas durante o processo de expatriação, gostaram da experiência e voltariam a repeti-la.

"Acho que eu sou o primeiro a incentivar as pessoas a fazer isso que fiz, não somente fora do país, mas também fora do seu Estado". (Hélio)

Percebemos a predisposição positiva do brasileiro, constitui um elemento facilitador do processo de 
adaptação, traço que per se já é uma vantagem num processo desafiador como a expatriação.

6.5 Oportunidades, desafios e aprendizados da expatriação

Entre as oportunidades, conforme Bianchi (2011), o crescimento profissional e pessoal foi evidenciado na emergência de um novo olhar menos preconceituoso em relação "ao outro", de forma similar, os participantes relataram que houve uma melhoria na forma como eles se relacionam com as pessoas e um aumento da autoestima no ambiente profissional. Vivenciar outra cultura e exercitar a autocrítica, a partir da própria cultura foi considerado um ganho para os expatriados. Nesse sentido, os quatro movimentos propostos por Fraga e Esteves (2004) foram vivenciados em maior ou menos intensidade pelos expatriados entrevistados:

"O balanço geral foi positivo, posso dizer lá eu tive oportunidade de viver em um país mais organizado que funciona melhor que aqui, $e$ onde as pessoas são mais respeitadas". (Marcos)

Entre os desafios destaca-se a necessidade de programas de capacitação intercultural que possibilitem o "trânsito harmonioso" dos expatriados, que Fraga e Esteves (2004) caracterizam como situação transcultural pelos diversos países em que atuam, assim como, políticas adequadas de repatriação. Cabe notar que a maioria dos expatriados relatava a falta do convívio com a família e amigos como um dos maiores desafios enfrentados no exterior, conforme Bianchi (2011). As dificuldades com a língua foram relatadas como um empecilho para estabelecer contatos com as pessoas da cultura local, os "sotaques" variados evidenciam a percepção de subculturas e de ambiências multiculturais, numa mesma cidade.

Como aprendizados fundamentais foram mencionados a possibilidade de lidar com a diversidade cultural, adquirir a competência intercultural e ter uma visão menos preconceituosa do "outro" (Fraga e Esteves, 2004).

"Hoje, eu consigo conviver com pessoas diferentes, consigo trabalhar com pessoas diferentes" (Francisco)

Notamos que o relacionamento interpessoal é indissociável do processo de expatriação e é justamente na interação que se da o fenômeno da alteridade.

\subsection{Dimensão sensorial, sentimentos e emoções}

A experiência no exterior suscitou a manifestação de diversos sentimentos e emoções: "agonia"; "angustia", "nervosismo", "surpresa", "felicidade", "insegurança", "solidão", "cansaço", "fadiga", "desconforto", "euforia", "esforço emocional". Sentimentos que vieram à tona em cada uma das fases da adaptação mencionados por Joly (2012). No que diz respeito aos sentidos, ficou claro que é pelos sentidos que conhecemos o mundo. O seguinte depoimento ilustra as sensações, sentimentos e anseios sentidos e vivenciados em outro lugar e cultura:

"Eu sou muito sensivel quanto ao cheiro [...] cheiros de pessoas me trazem boas lembranças, sabores, posso te dizer coisa boa sobre as comidas [...] o som seria interessante da geleira [...] A visão, a natureza, [...] 20 metros de geleira, um troço do além, a criação de Deus, tudo que vi, até o deserto de Talara, o por do sol, guardo como recordação; [...] Textura, tato, exemplo que eu senti, foi o casaco de penas, eu me senti abraçada pelo casaco, aqueceu meu coração, você esta distante de todo mundo, é importante, os abraços foram muito importante". (Larissa)

O sentimento de solidão fica claramente expresso neste depoimento. A necessidade do contato humano através dos abraços é uma característica própria do brasileiro e aparece quase em todos os depoimentos. Metaforicamente o casaco de penas transmitiu, para a entrevistada o "calor humano" necessário para ela sentir o "coração aquecido". Uma vez que ela sentia estar "distante de todo mundo". Constata-se que "há o predomínio da afetividade" na cultura brasileira. (Alencar-Rodrigues, Strey e Pereira, 2007).

Ao analisar os resultados desta pesquisa, o que se evidencia com os relatos é a fragilidade da relação organizacional, no âmbito da empresa à qual pertencem os entrevistados, com as necessidades relativas ao desenvolvimento de competências interculturais para os serviços globais. Fica claro que as experiências se limitam ao âmbito pessoal de cada expatriado, pois não foram reveladas iniciativas da empresa em questões culturais em nenhum momento do processo, isto é, nem na fase anterior, nem durante, nem no retorno do expatriamento. É 
possível, inferir a fragilidade ou talvez até momentânea ausência de políticas organizacionais em desenvolvimento de recursos humanos (Tanure, Evans e Pucik, 2007).

$\mathrm{Na}$ atualidade, essa lacuna é tanto um risco (ou um ônus) quanto um desperdício. No primeiro caso, torna-se claro que o despreparo pode gerar prejuízos para contatos e negócios internacionais da organização. O segundo caso, revela o ônus tanto financeiro quanto de imagem, ou ainda, de problemas profissionais e humanos para os expatriados envolvidos. No terceiro e último aspecto, o desperdício se mostra na complexidade de uma missão falida em que tudo se perde, inclusive, causando abalos à imagem e bloqueando possibilidades futuras para a empresa, além de temores antecipados a futuros expatriados (Nogueira, Barreto e Delgado, 2013).

\section{Considerações Finais}

Este artigo problematiza as experiências de brasileiros expatriados para desvendar os desafios e oportunidades com os quais se deparam em outras culturas. Primeiramente, os relatos dos processos de expatriação registram conotações positivas em termos das oportunidades profissionais e pessoais das missões internacionais. Por exemplo, alguns entrevistados mostraram-se satisfeitos com a experiência e dispostos a enfrentar novo processo de expatriamento. No entanto, destacamos com base nos resultados a fragilidade da chamada adaptabilidade antecipada, das estratégias de retorno, e do repatriamento com suas implicações no plano de carreira. Além disso, foi constatado que os expatriados não necessariamente passam pela etapa de "encantamento". Os principais desafios evidenciados pelos expatriados foram: a necessidade de programas de capacitação intercultural que os prepare adequadamente; a falta do convívio com a família e amigos; as dificuldades com a língua; a insegurança na volta por ausência de políticas de repatriação, e a inexistência de um plano de carreiras para os expatriados.

Entre as oportunidades e aprendizados do convívio, o crescimento profissional e pessoal foi constatado assim como a "revisão de valores" iniciais para lidar com a diversidade cultural, com o ganho de ter adquirido a competência intercultural que lhes permitiu ter um novo olhar, menos preconceituoso, com relação "ao outro". Desta forma, a compreensão e vivência dos "quatro âmbitos e movimentos culturais" assim como a adaptabilidade antecipada e a adaptabilidade dentro do país anfitrião (como ilustra a Figura 1), foi corroborada, quer por sua presença ou por sua falta.

Muitos dos entrevistados veem a expatriação como um divisor de águas, tanto na vida pessoal quanto profissional, assim, o papel da família é fundamental e necessário para cuidar da preparação para a missão internacional, a fim de que seja bemsucedida. No que diz respeito às características do brasileiro como facilitadores do processo de adaptação, destacam: flexibilidade, facilidade de comunicação e otimismo que, segundo os entrevistados, são características do povo brasileiro.

Evidenciamos que as iniciativas da área de GIRH ainda são tímidas e embora exista uma preocupação inicial nas empresas no que diz respeito à parte legal, de apoio social e logístico, de remuneração e benefícios, para poder lidar com os processos de expatriação, as ações para a preparação, isto é para o treinamento e desenvolvimento intercultural, considerados importantes pelos entrevistados somadas à repatriação, mostraram-se insuficientes.

Com relação ao processo de seleção, foi perceptível a primazia do critério técnico, assim como a natureza de "cargo de confiança", em detrimento de pessoas com competências comportamentais e interculturais. Conclui-se que a área de GIRH ainda tem a oportunidade de aproveitar a rica experiência dos expatriados para reformular as suas políticas e práticas no âmbito internacional, usufruindo do mindset global dos seus executivos.

A experiência no exterior suscitou a manifestação de diversos sentimentos e emoções que vieram à tona em cada uma das fases da adaptação, entre os quais se podem mencionar: "agonia"; "angustia", "nervosismo", "surpresa", "felicidade", "insegurança", "solidão", "cansaço", "fadiga", "desconforto", "euforia" e "esforço emocional", merecendo atenção do GIRH na preparação, no acompanhamento e no repatriamento. As sensações, sentimentos e anseios relatados, vivenciados pelos expatriados, Ihes possibilitou aguçar os sentidos a partir da experiência internacional e corroborou com a necessidade de "humanizar o processo de globalização", porque são essencialmente as "pessoas" e não apenas "mercadorias" e "capitais financeiros" os que transitam nela. 
Este artigo contribui para a literatura de GIRH pelas evidências de gestão à brasileira em uma área de conhecimento colonizada pelas práticas hegemônicas anglo-americanas. Em paralelo, contribui para o debate acerca do resgate da dimensão humana na gestão internacional. Por outro lado, em termos práticos, o artigo sugere aspectos que podem interferir no desempenho das EMNs nos processos de internacionalização, particularmente para os gestores envolvidos nas atividades internacionais, profissionais de Gestão de Pessoas, consultores, bem como os expatriados.

Consideramos fundamental que pesquisas futuras focadas na GIRH em empresas brasileiras, reconheçam que o fenômeno da expatriação é multifacetado, portanto, requer uma visão multidisciplinar para a sua melhor compreensão. Para tal devemos promover o diálogo com os campos de Psicologia Social, Antropologia, Sociologia e Comunicação Intercultural. Dentre os tópicos que devem ser privilegiados destacamos questões de gênero, adaptação da família, adaptação intercultural e repatriação segundo abordagem que privilegiem a dimensão humana.

\section{Referências}

- Aguzzoll, R.L. (2008). Gestão de pessoas internacional: como multinacionais brasileiras internacionalizam seus recursos humanos? In Gestão de pessoas: categoria acadêmica. Rio de Janeiro: Qualitymark.

- Alencar-Rodrigues, R., StReY, M. \& Pereira, J. (2007). Experiência Migratória: encontro consigo mesmo? Percepções de brasileiros sobre sua cultura e mudanças pessoais. Aletheia, 26, 168180. Recuperado em 20 de julho de 2016, de http://pepsic.bvsalud.org/scielo.php?script=sci_ar ttext\&pid=S141303942007000200014\&lng=pt\&tlng=pt

- BARDIN, L. (2011). Análise de conteúdo. São Paulo: Edições 70.

- BIANCHI, E. M. P. G. (2011, setembro). Gestão e Carreira Internacional. Repatriação - construindo elos entre ciclos. Encontro da ANPAD, Rio de Janeiro, Brasil, 35.

- BLACK, J. S., MENDENHALL, M. \& ODDOU, G. (1991). Toward a comprehensive model of international adjustment: an integration of multiple theoretical perspectives. Academy of Management Review, 16(2), 291-317.
- CALDAS, M. P., TONelli, M. J. \& LACOMBE, B. M. B. (2009, setembro). Políticas em Recursos Humanos Internacionais: faz sentido o debate entre abordagens críticas versus abordagens funcionalistas ao sul do equador?. Encontro da ANPAD, São Paulo, Brasil, 33.

- casanova, L. Las multinacionales latinoamericanas en los albores de una gran oportunidad. (2010). Revista de Administração de Empresas-RAE, 50(4), 439-445.

- CAZURRA, A. C. (2010). Multilatinas. Universia Business Review, 25,14-33. Recuperado em 14 de setembro de 2015, de https://ubr.universia.net/article/view/726/multila tinas.

- CHANLAT, J. F. (2012). Por uma antropologia da condição humana nas organizações In Chanlat, J.F. (Coord.), O indivíduo na organização: dimensões esquecidas (3a ed., vol. I, pp. 21-45). São Paulo: Atlas.

- CORSETTI, R.(2013). Desenvolvimento de pessoas com vistas à expatriação: um estudo em três multinacionais atuantes no RS. (Dissertação de Mestrado em Administração), UFRG, Rio Grande do Sul, Brasil. Recuperado de http://www.lume.ufrgs.br/bitstream/handle/1018 3/78440/000899575. pdf?sequence $=1$

- CRESWELL, J. (2014). Investigação qualitativa e projeto de pesquisa: Escolhendo entre cinco abordagens. (3a ed.). Porto Alegre: Penso.

- dellagnelo, E. \& Silva, R.(2005). Análise de conteúdo e sua aplicação em pesquisa na administração. In: VIEIRA, M. M. F; ZOUAIN, D. M. (Orgs.) Pesquisa qualitativa em administração: teoria e prática. Rio de Janeiro: FGV.

- DUtRA, J. (2002). Gestão de Pessoas: modelos, processos, tendências e perspectivas. São Paulo: Atlas.

- FDC. Fundação Don Cabral (2014). Ranking das transnacionais Brasileiras 2014: A força da marca Brasil na criação de valor internacional. Recuperado de http://www.fdc.org.br/blogespacodialogo/Docum ents/ranking_fdc_multinacionais_brasileiras 2014 . pdf

- FDC. Fundação Don Cabral (2015). Ranking das transnacionais Brasileiras 2015: A capacidade de adaptação cultural das empresas brasileiras no mundo. Recuperado de https://www.fdc.org.br/blogespacodialogo/Docu ments/2015/ranking_fdc_multinacionais_brasileir as2015.pdf 
- Fleury, A. \& FleuRY, M. T. L. (2012). Multinacionais Brasileiras -Competências para a internacionalização. (1a. ed.) Rio de Janeiro: FGV.

- FRAGA, V. (1998). Projeto de desenvolvimento intercultural: uma estratégia nos serviços globais. Revista de Administração Pública, 32(5), p. 99-124.

- $\quad$ fRAGA, V. \& ESTEVES, V. (2004). AIR TRANSPORT CHALLENGES: importance of cross cultural education and research. In: Global Business and technology navigating crisis and opportunities in global markets. GBATA, 10, África do Sul.

- FRAGA, V. (2009). Gestão pela formação humana: uma abordagem fenomenológica. (2a. ed.). Niteroi: Impetus, 2009.

- $\quad$ FREITAS, M. E. \& DANTAS, M. (2011). O estrangeiro e o novo grupo. RAE-Revista de Administração de Empresas, 51(6), 601-608. http://dx.doi.org/10.1590/S003475902011000600008

- GAllon, S., GARAY, A. B. S. \& Bitencourt, B. M. Expatriação como processo estratégico nas empresas internacionalizadas. Encontro da ANPAD, Rio de Janeiro, Brasil, 36.

- GAUlejAC, V. (2007). Gestão como Doença Social. São Paulo: Ideias e Letras.

- GIBBS, G. (2009). Análise de dados qualitativos. Porto Alegre: ArtMed.

- HOFSTEDE, G. (2003). Culturas e organizações: compreender a nossa programação mental. Lisboa: Gráfico Manuel A. Pacheco Ltda.

- JOly, A. (2012). Alteridade: ser executivo no exterior. In: Chanlat, J. F. (Coord.) O indivíduo na organização: dimensões esquecidas. (3. ed., vol. 1, p. 83-124). São Paulo: Atlas.

- LiMA, M. B. \& BRAGA, B. M. (2010). Práticas de recursos humanos do processo de repatriação de executivos brasileiros. Revista de Administração Contemporânea, 14(6), 1031-1053.

- LisboA, T. W. (2014). Cenas da diversidade no ambiente empresarial: os atuais fluxos migratórios internacionais para o Brasil e o desafio da interculturalidade. ORGANICOM, 11(21), 177-186.

- MANZON, F. S., JAEGER, M.A. \& KATO, H. T. (2010). Percepção das barreiras aos negócios internacionais: aspectos relacionados à internacionalização e expatriação. Revista Perspectiva, Erechim. 34(26), 33-45.

- McCRACKEN, G. (1998). The long interview. Newburry Park: Sage Publications.
- Merleau-PONTY, M. (2011). Fenomenologia da Percepção. São Paulo: Editora WMF Martins Fontes.

- MENDENHALL, M., PUNNETT, B. J. \& RICKS, D. (1995). Global Management. Massachussetts: Blakwell.

- MURITIBA, P. M., MURITIBA, S. N., CAMPANARIO, M. A. \& ALBUQUERQUE, L. G. (2010). International HR strategy in Brazilian technology multinationals. BAR - Brazilian Administration Review, 7, 325-344.

- BLACK, J. S., MENDENHALL, M. \& ODDOU, G. (1991). Toward a comprehensive model of international adjustment: an integration of multiple theoretical perspectives. Academy of Management Review, 16(2), 291-317.

- nogueira, A., BARReto, M. \& DElgado, M. (2013). Gestão de Recursos Humanos no Processo de Internacionalização. Internext - Revista Eletrônica de Negócios Internacionais, 8 (1) 48-6.

- ORSI, A. (2010). Gestão Internacional de pessoas: políticas de recompensas para expatriados por empresas brasileiras (Tese de Doutorado em Administração) Universidade de São Paulo, São Paulo, Brasil.

- PeRlMuter, H. V. (1969) The tortuous evolution of the multinational corporation. Columbia Journal of World Business, 4(1), 9-18.

- Peltonen, T. (2006). Critical theoretical perspectives on International Human Resources Management. In: Bjorkman, I., Stahl, G (ed.) Handbook of research in international human resource management, Cheltenham: Edward Elgar.

- ROSAL, A. S. R. Políticas de remuneração na expatriação de executivos: a compreensão dos gestores de recursos humanos internacional. Congresso do Instituto Franco-Brasileiro de Administração de Empresas, Gramado, Brasil, 8.

- Salgado, O. T. E. (2014). Programas de Expatriação e Repatriação: Políticas e Práticas de Recursos Humanos nas Transnacionais Brasileiras. (Tese de doutorado em Administração) Universidade Municipal de São Caetano do SulUSCS, São Caetano do Sul.

- SCHULER, R. \& TARIQUE, I. International HRM: A North America perspective, a thematic update and suggestions for future research. International Journal of Human Resource Management, 18(5), 15-43.

- SILVA, N. B., ORSI, A. \& NAKATA, L. E. (2013). Análise da Produção Acadêmica sobre Gestão 
Internacional de Recursos Humanos entre 2001 e 2011. ReCaPe-Revista de Carreiras e Pessoas, 3(3), 50-60.

- SPANGER, M. A. F. C. (2012). Glamour e sombras na expatriação de executivos e executivas globais: intercorrências no trabalho e na familia. (Tese de Doutorado em Tecnologia) Universidade Tecnológica Federal do Paraná, Curitiba, Brasil.

- tanure, B., eVANS, P. \& PUCIK, V. (2007). A Gestão de Pessoas no Brasil. Virtudes e Pecados Capitais. Estudos de Caso. Rio de Janeiro: ELSEVIER.
- tanure, B. \& DuARTE, R. G. (2006). Gestão Internacional. São Paulo: Saraiva.

- TUNG, R. L. Selecting and training procedures of U.S., European, and Japanese multinational corporations. (1981), California Management Review, 25(1), 57-71.

- WOOD, T. J.; TONELLI, M. J.; COOKE, B. (2012). Para onde vai a gestão de pessoas? GV-Executivo, 11(2), 20-24.

\section{SOBRE OS AUTORES}

- Patricia Asunción Loaiza Calderón é Mestre em Administração Pública-EBAPE/Fundação Getulio Vargas-FGV/RJ. Professora Adjunta do curso de Administração da UNIGRANRIO. Doutoranda em Administração pela Universidade Grande Rio. Tem experiência na área de Gestão de Pessoas, com ênfase na Gestão Intercultural. E-mail: patricialc@hotmail.com.ORCID:0000-0003-3996-6526

- Ana Lucia Malheiros Guedes é Ph.D. em Relações Internacionais - London School of Economics and Political Science-LSE. Professora Adjunta do Programa de Pós-Graduação em Administração da Unigranrio. Coordenadora do Grupo de Estudos Internacionais em Administração do PPGA na mesma instituição. E-mail: almguedes@gmail.com

- Rúbia Walquiria de Carvalho é Mestre em administração pela Universidade do Grande Rio. Gestora Pública do INCA - Instituto Nacional do Câncer, atuando principalmente nos temas: gestão hospitalar, gestão de contratos, redesenho de processos, gerência de projetos, câncer e saúde pública. E-mail: rubiawal@gmail.com 


\section{International management of human resources: intercultural adaptability in the expatriation of brazilians}

Patricia Asunción Loaiza Calderón, Ana Lucia Malheiros Guedes and Rúbia Walquiria de Carvalho

University of Grande Rio - UNIGRANRIO, Rio de Janeiro, RJ, Brazil

\section{ARTICLE DETAILS}

Article history:

Received 1 October 2014

Accepted 18 April 2016

Available online in 30 August 2016

Double Blind Review System

\section{Scientific Editor}

Eduardo Eugênio Spers

\section{Keywords:}

Expatriates

Intercultural adaptability

International human resources management.

\begin{abstract}
This paper problematizes the experiences of Brazilian expatriates to show the challenges and opportunities that they face in other cultures. Grounded on the literature, we emphasize the need to humanize the internationalization process because expatriation is a multidimensional phenomenon that requires a multidisciplinary approach. Its empirical contribution is to analize data collected through interviews with sixteen expatriates. The findings suggest that the process of expatriation is an issue that requires more attention from the area of International Management of Human Resources. We identify the challenges as the fragility of the so-called antecipated adaptability, of repatriation strategies, of the repatriation implications to the job plan, as well as, the need of specific programs of intercultural training. Otherwise, expatriation processes register positive aspects as the professional and personal opportunities in the assignments. Taking into consideration these findings, the area of International Management of Human Resources may incorporate the intense experiences of expatriates to reformulate policies and practices and, consequently, benefit from the global mindset.
\end{abstract}

(C) 2016 Internext | ESPM. All rights reserved!

Para citar este artigo:

Calderón, P. A. L.; Guedes, A. L. M. \& Carvalho, R. W. (2016). Gestão internacional de recursos humanos: Adaptabilidade intercultural na expatriação de brasileiros. Internext - Revista Eletrônica de Negócios Internacionais, 11 (2), 6-20.

Para acessar este artigo: http://dx.doi.org/10.18568/1980-4865.1126-20 